\title{
Bronchial Anthracosis-Anthracofibrosis: Potential Causes and Clinical Features
}

To the Editor,

I read the manuscript "Bronchial Anthracosis-Anthracofibrosis: Potential Causes and Clinical Features," written by Uçar et al. (1), in the last issue of Eurasian Journal of Pulmonology with great interest. Anthracosis, a form of pneumoconiosis, is most commonly seen in coal workers. Air pollution, biomass smoke, and cigarette smoke are also known as other environmental factors for anthracosis (2). The term "anthracotic" is usually used to describe coal and other black pigments of which carbon is a major constituent. Characteristically, coal deposits are present as black plaques in the bronchi $(2,3)$. The term "bronchial anthracofibrosis" is of fairly recent origin and has come to define a clinical entity with bronchial lumen narrowing and anthracotic pigmentation visible on bronchoscopy. First reported from Korea, it was predominantly seen in non-smoking ladies with a longstanding history of exposure to wood smoke used for either food cooking or heating. The luminal narrowing and anthracotic pigmentation were most commonly observed in the right middle lobe $(2,3)$. The CT findings have been reported to include smooth bronchostenosis and peribronchial lymph nodes, along with peripheral atelectasis (2-4).

One hundred nine patients with a mean age of $67.8 \pm 9.8$ years were included in this retrospective study, and over half of them (52.3\%) were female. They reported that $32.1 \%$ of the cases were smokers, $61 \%$ had the biomass exposure, and $4 \%$ had occupational exposure and disease (1). In our prospective study (2), among 1541 patients who underwent bronchoscopy in our bronchoscopy unit between 2006-2008, 104 patients with anthracosis were included. The mean age was $61.3 \pm 13.3$ years, and nearly half of them (47.1\%) were also female; $46.1 \%$ of patients had a history of cigarette smoking. In $38.3 \%$ of patients, exposure to mineral dust or biomass in their job was observed, and $45.7 \%$ of them were housewives. In all of the patients, biomass exposure was found because of the fuel used for heating or in kitchens.

It was very interesting that regarding the geographical location, we found that the majority of the patients (38.5\%) was from the Black Sea region, especially from Kastamonu. It is a city in the northern part of Turkey having costal borders with the Black Sea. The heavily forested geographical feature of the Black Sea region and widespread use of wood for heating or as fuel in the kitchen may be explanations for the high rates of biomass exposure in this part of Turkey. Since the study of Uçar et al. (1) was retrospective, the data of geographic location of patients were not given. If this information had taken part in the study, it would be important in terms of our national data. We could not find any literature data about the geographical distribution of anthracofibrosis cases from Turkey. We propose that these patients with anthracosis from that region of Turkey should be evaluated in another prospective trial.

The presenting clinical symptoms were cough (71.2\% vs $58.7 \%)$ and dyspnea (57.7\% vs $49.5 \%)$ in our study (2) and the study of Uçar et al. (1). Radiographic abnormality is also an important finding in this group of patients. In their study, the most common radiological abnormality was atelectasis $(65.1 \%)$, whereas it was consolidation $(51.9 \%)$ in our study, which was the second most common radiological finding in the other study (55.0\%). They also reported that there was a statistically significant correlation between the bronchial anthracofibrosis and atelectasis ( $p=0.003$ ). On bronchoscopy, the left upper lobe bronchus was the most commonly involved site in our study, and it was almost equal for the right and left upper lobe bronchi in the study of Uçar et al. (1).

Tuberculosis is an important disease that can be seen often together with anthracosis. Both studies reported that active tuberculosis was diagnosed in these bronchial anthracosis/anthracofibrosis cases (6.7\% vs $11.0 \%)$. These two studies show that malignancy is another very important disease that must be kept in mind in this group of patients (10.6\% vs $10.1 \%)$. Bronchial anthracofibrosis may lead to recurrent pneumonia.

These two studies represent that among patients who undergo routine bronchoscopy, anthracosis and anthracofibrosis are diagnoses that may easily be missed or findings may be attributed to other causes. Thorough clinical evaluation and close follow-up of patients are required, since tuberculosis, pneumonia, and malignancy may be associated with bronchial anthracofibrosis. Large-scale, country-wide studies should be conducted for the determination of epidemiological data of bronchial anthracosis and anthracofibrosis in our country, in which a high rate of biomass exposure is found. 
Sevda Şener Cömert

Clinic of Pulmonary Diseaes, Dr. Lütfi kırdar Training and Research Hospital, İstanbul, Turkey

Address for correspondence: Sevda Şener Cömert, Clinic of Pulmonary Diseaes, Dr. Lütfi kırdar Training and Research Hospital, İstanbul, Turkey

E-mail /E-p osta: sevdasener2@yahoo.com

Received Date / Alındığı Tarih: 13.04.2014

Accepted Date / Kabul Tarihi: 17.04.2014

(c) Copyright 2014 Turkish Respiratory Society (TRS)

Eurasian J Pulmonol 2014

DOI: 10.5152/ejp.2014.05579

- Available online at www.eurasianjpulmonol.com

\section{REFERENCES}

1. Uçar EY, Araz Ö, Akgün M, Meral M, Sağlam L, Kaynar H, et al. Bronchial anthracosis-anthracofibrosis: Potential causes and clinical features. Euras J Pulm 2014; 16: 17-20.

2. Comert SS, Dogan C, Caglayan B, Fidan A, Kiral N, Salepçi B. The Demographic, Clinical, Radiographic and Bronchoscopic Evaluation of Anthracosis and Anthracofibrosis Cases. J Pulmonar Respirat Med 2012; 2: 2. [CrossRef]

3. Castranova V, Vallyathan V. Silicosis and coal workers' pneumoconiosis. Environ Health Perspect 2000; 108: 675-84. [CrossRef]

4. Kim HY, Im JG, Goo JM, Kim JY, Han SK, Lee JK, et al. Bronchial anthracofibrosis (inflammatory bronchial stenosis with anthracotic pigmentation): CT findings. AJR Am J Roentgenol 2000; 174: 523-7. [CrossRef] 